$\mathbb{P}$ periodica polytechnica

Civil Engineering

57/2 (2013) 185,190

doi: 10.3311/PPci.7173

http://periodicapolytechnica.org/ci

Creative Commons Attribution (1)

RESEARCH ARTICLE

\section{Method for identification of the initial loss of combined sewer catchments}

\author{
Balázs Istók / Gergely Kristóf
}

Received 2012-11-29, revised 2013-04-23, accepted 2013-05-28

\begin{abstract}
Intense, short periods of rainfall cause the greatest number of operational overflows, leading to the discharge of untreated sewage in combined sewerage systems of large cities. The annual amount of pollution can be estimated based on meteorological, orographic, surface coverage and hydraulic information, by using a detailed hydraulic model of the sewerage system. The most widely used hydrological models require input for the initial loss in order to define the amount of water remaining in the catchment, which decreases the load of the sewer and potentially, the amount of overflow. Earlier measurements of the initial loss were made only in rainwater channels. The results range from 0-6 $\mathrm{mm}$ in urban territory, which makes the case-by-case identification of this model parameter very important. A methodology is presented in this paper for calculating the amount of initial loss in a combined system catchment without any on-site measurements. The initial loss was identified for a 4500 ha catchment of Budapest. In addition, the dependence of the initial loss on the environmental temperature was analysed.
\end{abstract}

\section{Keywords}

Combined sewer $\cdot$ Hydrological model $\cdot$ Initial loss $\cdot$ Surface runoff . Urban drainage

\section{Balázs Istók}

Department of Fluid Mechanics, Budapest University of Technology and Economics, Bertalan Lajos u. 4-6., H-1111 Budapest, Hungary e-mail: istok@ara.bme.hu

\section{Gergely Kristóf}

Department of Fluid Mechanics, Budapest University of Technology and Economics, Bertalan Lajos u. 4-6., H-1111 Budapest, Hungary

e-mail: kristof@ara.bme.hu

\section{Introduction}

Numerical simulation is widely used in the hydrodynamic analysis of sewer networks. Models range from simple software, such as KAREN [13] or CityDrain [1] that calculate only rainwater runoff from impervious surfaces, to very complex urban drainage models. Examples of the latter are MOUSE [5], Infoworks [17] or Kanal++ [14], which model both complex surface runoff and channel/pipe flow, including transition from un-pressurised to pressurised pipe flow.

The model, in most cases, comprises four individual parts: the rainfall input, the hydrological surface process, the hydrodynamics of surface flow and the hydrodynamics of the sewer [16]. The most common hydrological models of surface processes need input for the initial loss (hollow loss, depression storage), known as the rainfall threshold, which defines the minimum rainfall necessary before surface runoff occurs from the catchment [6].

In the case of natural catchment areas, the magnitude of initial loss is typically $0-60 \mathrm{~mm}$, with approximately $22 \mathrm{~mm}$ expected value [7]. For Hungarian dense land $6.6 \mathrm{~mm}$ was proposed by Csoma and Varga [4]. However, it is only a fraction of this value in strongly urbanised areas. According to Boyd [2], it ranges from $0-6 \mathrm{~mm}$ with a $1.4 \mathrm{~mm}$ average, which is in line with several previous studies: Tholin and Keifer [15] Chicago USA, $1.6 \mathrm{~mm}$; Melanen and Laukkanen [11] Finland, 0.4 to $1.0 \mathrm{~mm}$; Hollis and Ovenden [9] GBR, $0.5 \mathrm{~mm}$, for roof and street areas. No measured hollow loss data are available for catchments of combined sewer systems, which is the most typical kind of sewer system in big cities.

Initial loss is calculated as the offset value of a fitted linear function on the rainfall depth to runoff depth diagram of the investigated catchment. Some authors [2] suggest a fitted piecewise linear function of 2-3 segments in the rainfall/runoff diagram to account for the runoff volume coming from areas of different permeability. The non-linearity of the rainfall/runoff diagram becomes more pronounced for large pervious catchment areas. The measured rainfall and runoff characteristics of small amounts of rain display a large scatter, which makes the offset of the fitted trend uncertain. 


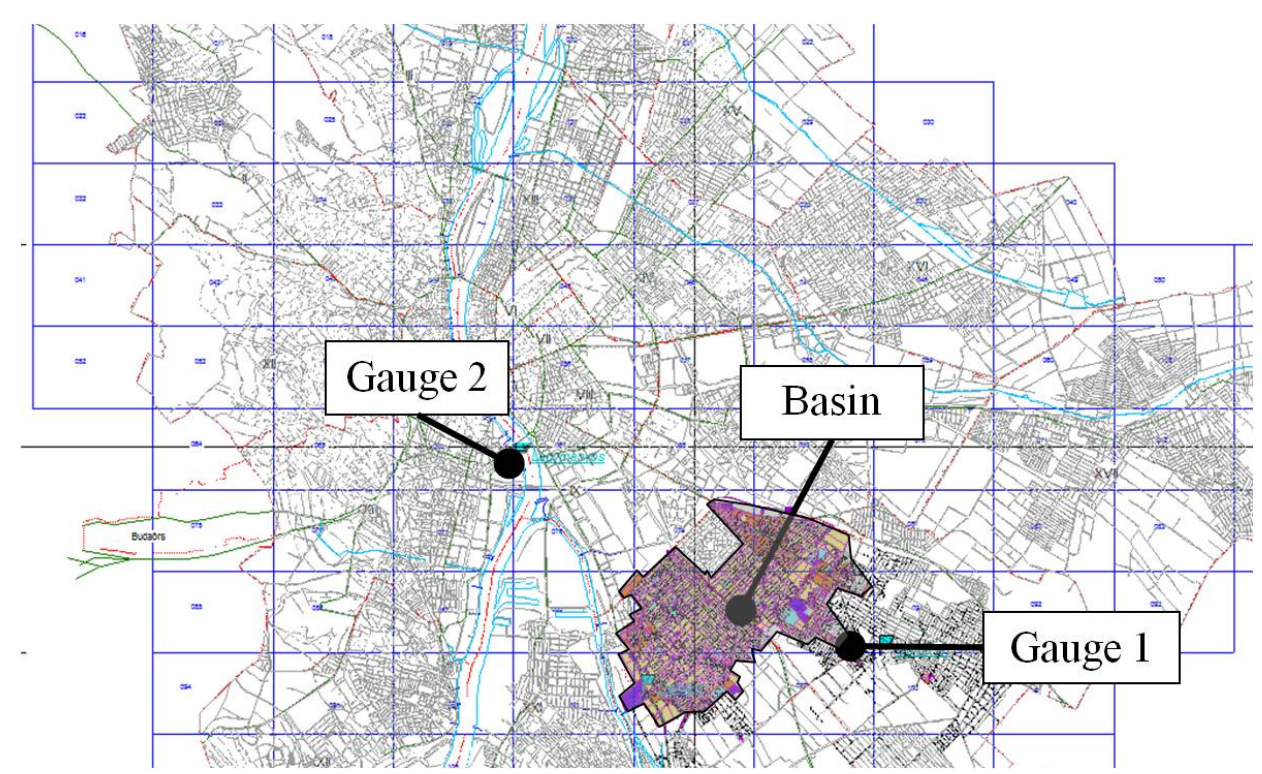

Fig. 1. Catchment area, rainfall gauges and sewage treatment plant

In our present study, the amount of mixed water runoff originating from a large catchment area of Budapest was investigated at the treatment plant of Dél-Pest over a three-year period. Methods for defining the amount of rainwater received at the treatment plant and for calculating the hollow loss will be introduced; furthermore, the dependence of hollow loss on environmental temperature will be analysed.

Between 2005 and 2007, $67 \%$ of rain events in the Dél-Pest catchment area fell in the range of $0-5 \mathrm{~mm}$. Therefore, the calculated amount of rainwater received by the treatment plant is very sensitive to the accurate setting of the initial loss, as is the total amount of overflows. The presented methodology can be applied in any combined sewerage systems for identifying the initial loss, which is specific for the investigated catchment, thereby increasing the accuracy of model predictions.

\section{The investigated area}

\subsection{Catchment area}

The data used in our calculations were the measured flowrate of inflowing water in the sewage treatment plant of Dél-pest (DSZTV). Measurement data with 3-minute resolution were processed for the years 2005-2007.

The treatment plant receives wastewater from four districts of Budapest, which have a population of 280000 . The total area of the catchment is 4500 ha and the part of it closest to the treatment plant is a combined sewer catchment. According to geoinformatical calculations, the size of the effective impervious area is 391 ha.

Multi-storey buildings and blocks of flats are characteristic of the combined sewer part of the area. The average surface slope of the area is approximately $1 \%$. Roof water and street water connects to the drainage system in almost all cases.

Drained water is measured in the inlet pipeline of the treatment plant, which is preceded by a storm water separation structure, limiting the flow rate to $4500 \mathrm{~m}^{3} / \mathrm{h}$.

\subsection{Rainfall intensity measurements}

The Hungarian Meteorological Service provided rainfall intensity data from two gauging stations in the catchment (see Fig. 1), which had 10-minute temporal resolution and $0.1 \mathrm{~mm}$ rainfall height resolution. Linsley et al. [10] suggested that for an experimental catchment, the minimum requirement for the number of stations is 1 gauging station per 2500 ha, in our case it was 2 per 4500 ha.

\section{Analysis of dry weather inflow data}

The time resolution of the collected flow-rate data was 3 minutes and the collected data were averaged over 30 minutes in order to filter out fluctuations due to switching the pumps on the catchment. First, flow rate data for all days with precipitation were excluded. The daily evolution of flow rate was than averaged over a period of one month for the same days of the week. The results of our calculations are shown in Fig. 2.

The evolution of influent sewage water is very similar on working days (Monday-Friday) and on the weekend. The average amount of influent sewage water $\mathrm{Q}$ was defined for these two groups of days according to the following expression of the 30 -minute average of the measured flow rate $(\mathrm{q})$ :

$$
Q_{a, i}=s \cdot q_{a, i}+(1-s) \cdot Q_{a, i-1}
$$

in which $a$ corresponds to the type of weekday ( $a=1$ workday, $a=2$ weekend), $i$ is the time index and $s=0.25$.

Surplus flow rates caused by rainwater were obtained by subtracting the moving averaged dry weather flow rates from smoothed (30-min averaged) instantaneous measurements. These differences in dry weather cases were investigated and were found having a normal distribution. The interval $\pm 250 \mathrm{~m}^{3} / \mathrm{h}$ (two times the standard deviation of the differences) around the average $\left(0 \mathrm{~m}^{3} / \mathrm{h}\right)$ includes $95 \%$ of the data points. Differences only above this threshold $\left(250 \mathrm{~m}^{3} / \mathrm{h}\right)$ were considered in order to filter out data scattering. 


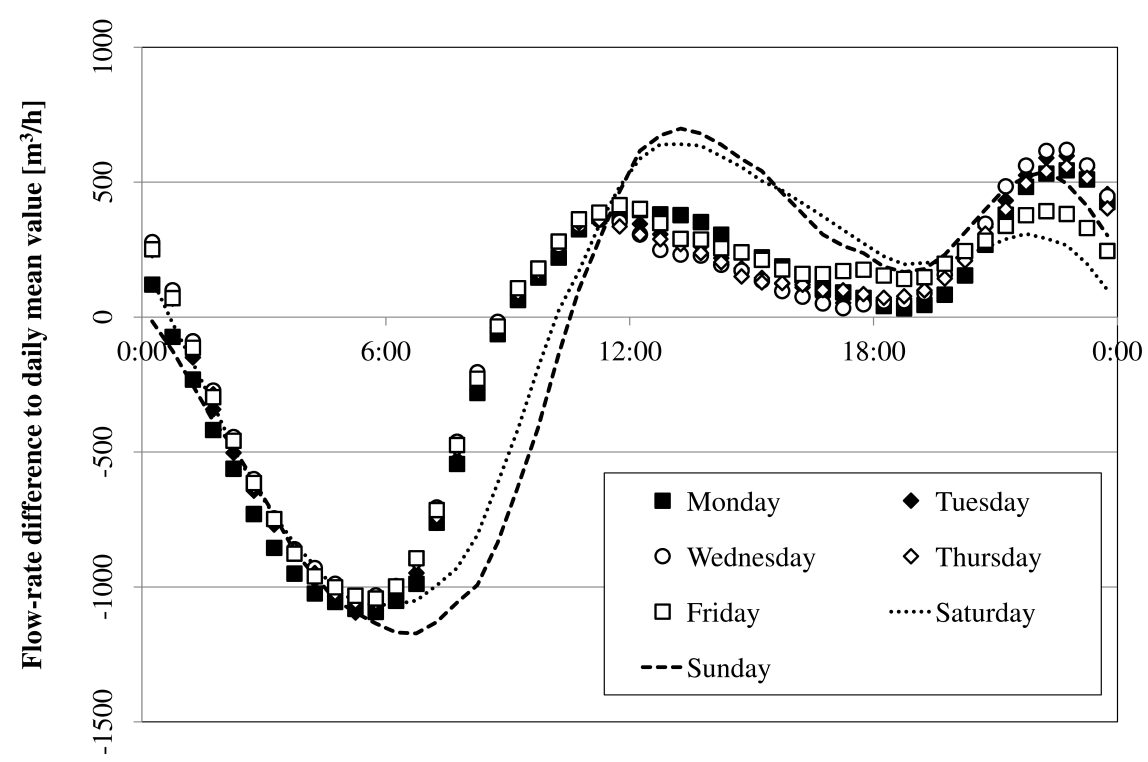

Fig. 2. Monthly average of the daily evolution of the fluctuating component of sewage flow rate on each day of the week

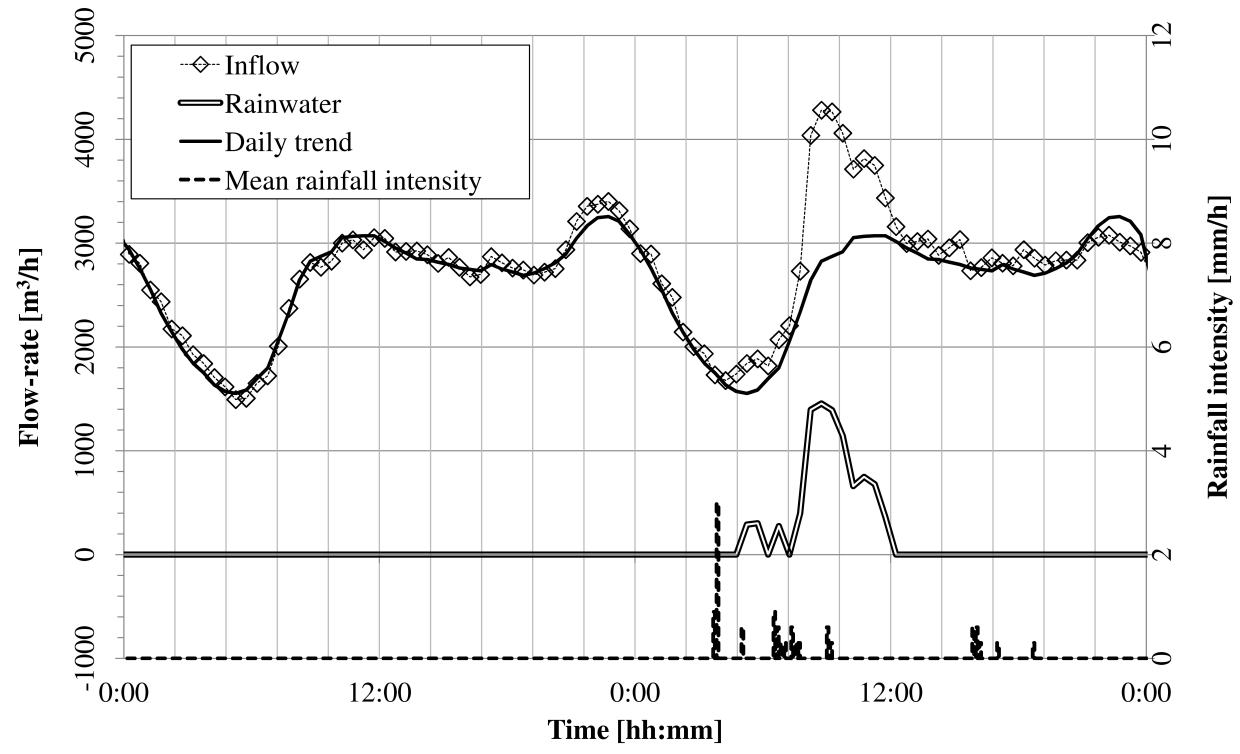

Fig. 3. Influent rainwater and mean rainfall intensity at Gauge 1 and 2 
As can be seen from Fig. 3, after defining influent rainwater, the integration of rainwater flow rate following a rainfall event is possible. The influent amount divided by catchment area was further analysed as a function of rainfall depth. The latter can be calculated by integrating the measured intensity data for individual rainfall events.

\section{Defining rainfall events}

Calculations were based on data measured by Gauge 1 in DélPest but data from Gauge 2 in Lágymányos were also used when corrections and restrictions were made. The 3 -year rainfall intensity data with 10-minute resolution were decomposed to a series of independent rainfall events. The temporal extent of dry periods between two elements needed to be reduced in order to save calculation time. The minimum necessary length of dry period was obtained from the detailed hydraulic simulation model of the sewerage system, as the duration needed to achieve the volumetric flow rate of the dry period outflow after an intense shower. This duration depends on the characteristics of the catchment area and therefore, it had to be determined specifically for the examined catchment area.

From the 3-year precipitation intensity datasets, 330 rainfall events were identified. Extremely small rainfall events, where rainfall height was less than $0.3 \mathrm{~mm}$, were filtered out. The resolution of the rainfall measurement was $0.1 \mathrm{~mm}$ and therefore, $0.3 \mathrm{~mm}$ could be detected; however, such rainfall amounts are not expected to cause accurately measurable surplus water yields.

The influent flow-rate is limited by a safety spillover, which separates flow rates over $4500 \mathrm{~m}^{3} / \mathrm{h}$. Regarding the initial loss, rainfall of small height has much greater significance and thus, the integral of the influent rainwater amount was limited at $5000 \mathrm{~m}^{3}$. This volume is equivalent to $1.28 \mathrm{~mm}$ rainfall depth falling on the effective area of the impervious catchment (391 ha).

In Fig. 4, 330 rainfall events are shown in a rainfall-runoff diagram. A regression line, which is suggested in reference sources [12], [3] would define the initial loss. Fig. 4 illustrates that the events show high scatter and therefore, the uncertainties in the parameters of a regression line would be unacceptably high. Filtering conditions (FC) based on physical principles and a correction $(\mathrm{CO})$ was applied to reduce dataset scattering.

\subsection{Snow and frozen soil (FC1)}

Snow events have to be filtered out from other types of precipitation because they enter the sewage system with an uncertain delay. One part of the snow melts but an unknown portion remains on different surfaces. Furthermore, soil may freeze in cold weather, which reduces the infiltration capacity of soil and therefore, runoff water may arrive from areas from which it normally does not. In order to eliminate these uncertainties, all events for which the temperature was below $1^{\circ} \mathrm{C}$ at the onset were removed.

\subsection{Repeated rainstorms (FC2)}

A significant part of the rainfall series occurred with one rainfall event occurring soon after another. In these cases, rainwater presumably remained in small pools of the catchment area, which reduced hollow loss. Rainfall events that occurred within 24 hours omitted from further research.

\subsection{Second gauge involved (CO1)}

Gauge 1 is located in the investigated basin but in some cases, the results showed that the measured rainfall values were not representative for the whole area. In order to increase the precision of rainfall measurement, the second gauging unit (Gauge 2) was taken into account. The mean rainfall was then calculated as the average of two measured values.

\subsection{Rain with non-estimable spatial distribution (FC3)}

After adding the second unit (Gauge 2), some spatially undefined events could be neglected. If rainfall was detected only at the first unit, its spatial distribution could be uneven, increasing the deviation of the results and therefore, all rainfall events detected at one gauge only were filtered out.

\section{Regression function}

A piecewise linear function of three sections was fitted to the dataset. The first horizontal segment represents the rainfall threshold. The second segment refers to the proportional part of the events; increasing rainfall increases the runoff amount. The third segment corresponds to intense rainfall events when the limiting condition was operational. Using the method of least squares, the margins of the segments were optimised to the remaining 51 events. The resulting graph can be seen in Fig. 5. The confidence interval of the regression function was calculated [8] after checking the normality of the distribution of the dataset by chi probe.

\section{Evaluation of the filtering conditions and correction}

The effectiveness of the filtering conditions was evaluated by means of deviation of the data points from the regression function in the proportional segment in the absence of the given FC or CO. This part of the regression function influences the value of the initial loss. The deviation was calculated for the runoff value of the data points. The results are shown in Table 1 .

As can be seen from Table 1, the deviation of the measured runoff values would be at least 2 times higher in the absence of any of FC1, FC2, FC3 or CO1, which underlines the importance of data conditioning.

\section{Effect of temperature on the initial loss}

It can be supposed that a warmer surface will cause more evaporation than a cold one. Evaporation increases the amount of rainwater that does not flow into the sewer, potentially causing an apparent initial loss. 


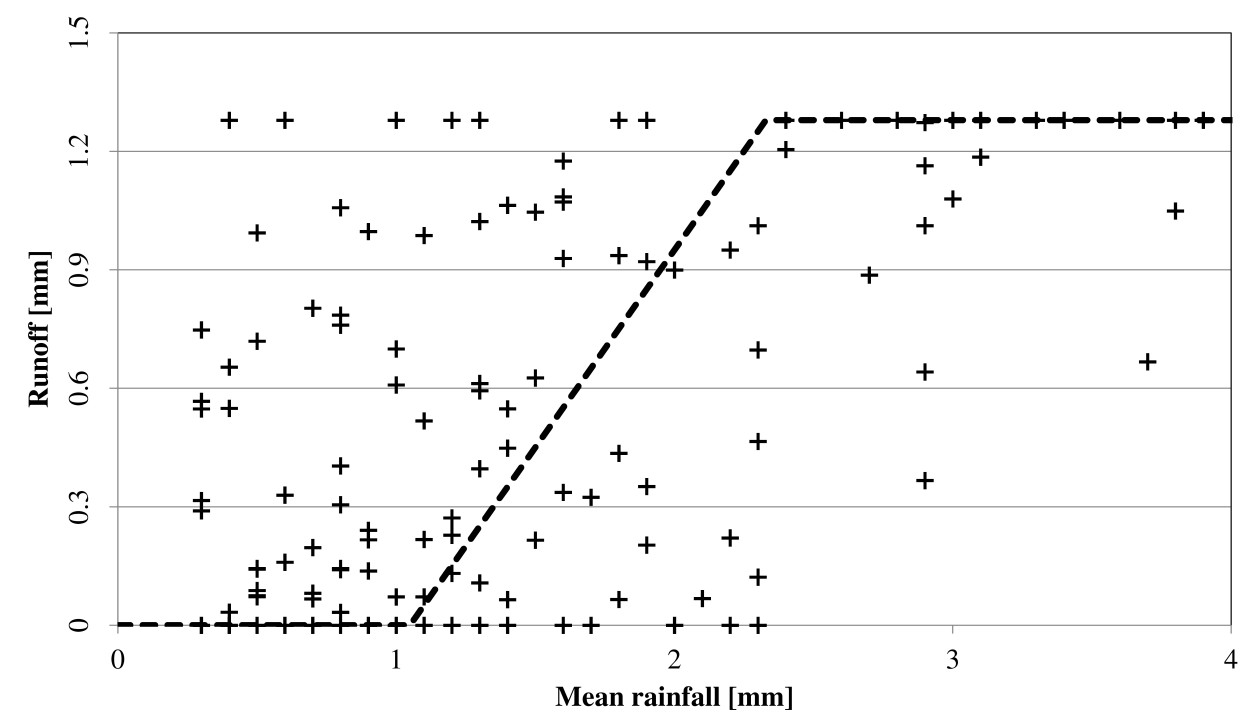

Fig. 4. Rainfall events from 3-year data

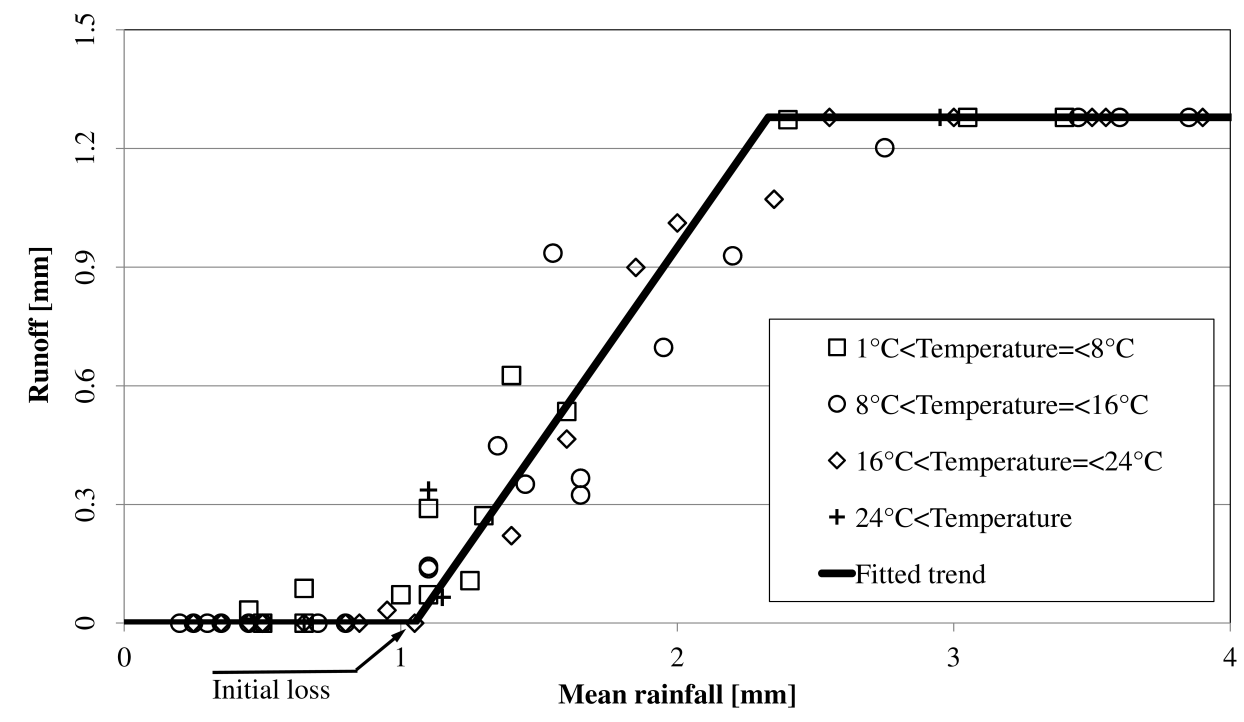

Fig. 5. Rainfall-runoff diagram marked with ambient temperature regimes

Tab. 1. Reduction of data scattering by various filtering conditions and correction

\begin{tabular}{cc}
\hline Deactivated filtering condition or correction & Deviation of the runoff $[\mathrm{mm}]$ \\
\hline All corrections and filtering conditions are active & 0.2 \\
\hline FC1 deactivated (Snow or frozen soil) & 0.5 \\
\hline FC2 deactivated (Recurred rains) & 0.58 \\
\hline CO1 deactivated (Only Gauge 1 used) & 0.4 \\
\hline FC3 deactivated (Rain with uneven spatial distribution) & 0.79 (only 1 value)
\end{tabular}


For this investigation, the temperature measurement of the Lágymányos OMSZ station was used. The rainfall-runoff diagram supplemented with the environmental temperature values can be seen in Fig. 5 .

No significant correlation can be observed between the environmental temperature and the initial loss in the $1-28^{\circ} \mathrm{C}$ temperature range.

\section{Conclusions}

The major novelty of this article is the description of a methodology for the identification of initial loss of combined sewer catchments. The research was motivated by the high sensitivity of calculated spillover amount for the initial loss assumed in the hydraulic model. Only a few measurements are available for the initial loss in urbanized area and the variance of this dataset suggests case by case identification of this model parameter. Since most large cities operate combined sewerage systems it was necessary to develop a method for estimating the initial loss for combined system catchments on the basis of commonly available data.

Flow-rate of the influent mixed (sewage + rain) water at a sewage treatment plant of a large catchment area in Budapest was investigated in correlation with meteorological data for a three-year period. The measured mixed water flow rate was separated into dry weather sewage and rainwater. Rainfall events were identified in a 3-year rain gauge dataset. Effective rain height was calculated by dividing the integral of rainwater inflow by the effective impervious area of the investigated catchment.

The rain events displayed large scatter on the rainfall-runoff diagram, which could be considerably decreased by assuming three filtering conditions and a correction method. Elimination of repeated rain events within a 24-hour time interval (FC2) was found to be the most effective filtering condition, decreasing the variance of data points on the rainfall-runoff diagram by a factor of three. Omission of those rain events that were observed in only one of the two rain gauge stations (FC3) also had a massive effect on the variance, but the number of the additional investigated data points was low.

By using the proposed filtering conditions and correction a regression function could be fitted with high confidence. The zero runoff point of the regression function defines the initial loss. The value of the initial loss was $1.05 \pm 0.064 \mathrm{~mm}$ with $95 \%$ confidence level for the investigated combined sewer catchment (Délpest Treatment Plant).

Direct correlation between the value of the initial loss and the environmental temperature could not be found in the $1-28^{\circ} \mathrm{C}$ temperature range.

\section{Acknowledgements}

Special thanks to the Budapest Sewage Works Ltd. (FCSM) for their assistance and measurement data of the treatment plant and also to The Hungarian Meteorological Service (OMSZ) for the gauge measurements.

This work has been developed in the framework of the project "Talent care and cultivation in the scientific workshops of BME" project. The project is supported by the grant TAMOP-4.2.2/B10/1-2010-0009.

\section{References}

1 Achleitner S, Möderl M, Rauch W, CITY DRAIN An open source approach for simulation of integrated urban drainage systems, Environmental Modelling \& Software, 22(8), (2007), 1184-1195, DOI 10.1016/j.envsoft.2006.06.013.

2 Boyd MJ, Bufill MC, Knee RM, Pervious and impervious runoff in urban catchments, Hydrol. Sci. J., 38(6), (1993), 463-478.

3 Calomino F, Veltri $\mathbf{P}$, Rainfall-runoff in a small urban basin: experimental results from Luzzi, (Goteborg, Sweden, 1984), In: 3rd International Conference on Urban Storm Drainage, Chalmers Univ. Technology; Göteborg, Sweden, 1984, pp. 223-231.

4 Csoma R, Varga I, Knee RM, Pervious and impervious runoff in urban catchments, Hydrol. Sci. J., 38(6), (1993), 463-478.

5 DHI, MOUSE Surface Runoff Models Reference Manual, D. Software; Horsolm, Denmark, 2002.

6 Dotto CBS, Kleidorfer M, Deletic A, Rauch W, McCarthy DT, Fletcher TD, Performance and sensitivity analysis of stormwater models using a Bayesian approach and long-term high resolution data, Environmental Modelling \& Software, 26(10), (2011), 1225-1239, DOI 10.1016/j.envsoft.2011.03.013.

7 El-Kafagee M, Rahmana A, A study on initial and continuing losses for design flood estimation in New South Wales, ( Perth, 2011), In: 19th International Congress on Modelling and Simulation, 2011, pp. 3782-3787.

8 Felix M, Bláha K, Matematikai Statisztika a Vegyiparban, Mû́szaki Könyvkiadó; Budapest, Hungary, 1964.

9 Hollis GE, Ovenden JC, The quantity of stormwater runoff from ten stretches of road, a car park and eight roofs in Hertfordshire, England. Hydrol. Processes 2, (1988), 227-243.

10 Linsley R. K., Kohler MA, Paulhus JLH, Hydrology for Engineers, McGraw-Hill; New York, 1975.

11 Melanen. M, Laukkanen. R, Dependence of runoff coefficient on area type and hydrological factors, (Littleton, Colorado, USA, 1981), In: 2nd Int. Conf. Urban Storm Drainage, Water Resources Publications; Colorado, USA, 1981, pp. 404-410.

12 Miller RA, Mattraw HC, Jennings ME, Statistical modelling of urban storm water processes, Int. Symp. on Urban Stormwater Management, (Broward County Florida, 1978), In:, Univ. Kentucky Publications; Kentucky, 1978, pp. 269-273.

13 Rauch W, Kinzel H, KAREN User Manual, Hydro-IT GmbH; Innsbruck, Germany, 2007.

14 Tandler R, ++SYSTEMS User Manual, Tandler.com GmbH; Buch am Erlbach, Germany, 2009.

15 Tholin AL, Keifer CJ, The hydrology of urban runoff, Trans. ASCE, 125, (1960), 1308-1379.

16 Thorndahl S, Schaarup-Jensen K, Comparative analysis of uncertainties in urban surface runoff modelling, (Lyon, France, 2007), In: Novatech 2007 6th Int. Conf. on sustainable techniques and strategies for urban water management, 1978, http://hdl.handle.net/2042/25435

17 Wallingford Software, Infoworks CS Help, Wallingford Software; United Kingdom, 2009 